\title{
O Conceito de Executivo Central e Suas Origens ${ }^{1}$
}

\author{
Rosinda Martins Oliveira ${ }^{2}$ \\ Universidade Estácio de Sá
}

\begin{abstract}
RESUMO - O interesse no Executivo Central (EC) cresce a cada dia em vista da observação de disfunção executiva em patologias como o transtorno do déficit de atenção. Entretanto, embora existam referências a esse conceito na literatura nacional, não há nenhum estudo dedicado a um detalhamento teórico a seu respeito. Este trabalho apresenta o conceito de Executivo Central e suas origens teóricas. O EC se caracteriza como um coordenador das operações mentais. A concepção desse sistema remonta à dicotomia entre processos controlados e automáticos. O EC foi explorado na Psicologia soviética e, no contexto da teoria do processamento da informação, seu funcionamento foi explicitado no modelo composto por um Sistema Atencional Supervisor e um organizador pré-programado. Conhecer as origens do conceito de Executivo Central pode trazer novas idéias sobre o seu desenvolvimento normal ou patológico.
\end{abstract}

Palavras-chave: sistema atencional supervisor; funções executivas; psicologia cognitiva.

\section{The Central Executive Concept and its Origins}

\begin{abstract}
The interest in the Central Executive grows each day in view of the observation of executive dysfunction in pathologies like TDAh. However, although references to this concept exist in the specialized literature in Brazil, there is a lack of theoretical studies about this subject. This article presents the Central Executive concept and its theoretical origins. The Central Executive is a coordinator of mental operations. The conception of this system goes back to the dichotomy between controlled and automatic processes. It was explored in Russian Psychology and, in the context of cognitive psychology, its functioning was explained in a model composed of a Supervisory Attentional System and a prescheduled organizer. Knowing the origins of the Central Executive concept may bring new ideas about its normal or pathological development.
\end{abstract}

Key words: supervisory attentional system; executive functions; cognitive psychology.

O Executivo Central tem sido alvo de interesse desde sua proposição por Baddeley e Hitch (1974), enquanto um componente da memória de trabalho. No entanto, embora exista um número importante de artigos experimentais que abordam este conceito na literatura relativa a Psicologia Cognitiva, em nossa língua (por exemplo, Charchat-Fichman, Caramelli, Sameshima \& Nitrini, 2005; Charchat-Fichman, Nitrini, Caramelli \& Sameshima, 2001; Galera \& Fuhs, 2004; Lopes, Lopes \& Galera, 2005; Malloy-Diniz \& cols., 2004; Parente, Sparta \& Palmini, 2001; Rozenthal, Laks \& Engelhardt, 2004), estudos teóricos, em português, a respeito desse conceito têm sido extremamente raros (Helene \& Xavier, 2003).

A literatura internacional conta com um conjunto de dados cada vez mais substancial indicando a presença de disfunção do Executivo Central em patologias do desenvolvimento como, por exemplo, o transtorno do déficit de atenção (TDAH) (Karatekin, 2004; Martinussen, Hayden, HoggJohnson \& Tannock, 2005; Roth \& Saykin, 2004; Weyandt, 2005), dificuldade específica de aprendizagem (Brosnan \& cols., 2002; Henry, 2001; Jeffries \& Everatt, 2004; Sikora,

1 Este trabalho e sua autora receberam financiamento do Conselho Nacional de Desenvolvimento Científico e Tecnológico - CNPq.

2 Endereço: Rua Xavier da Silveira, 86/702, Copacabana, Rio de Janeiro, RJ, Brasil 22061-010.E-mail: rosindaoli@terra.com.br
Haley, Edwards \& Butler, 2002; Stanczak \& Triplett, 2003) e transtornos invasivos do desenvolvimento (Happe \& Frith, 1996; Hill \& Frith, 2003; Planche, 2002; Shamay-Tsoory, Tomer, Yaniv \& Aharon-Peretz, 2002). Esta constatação revela a importância do conhecimento desse conceito para um psicólogo interessado em Psicologia Cognitiva, seja em termos da pesquisa ou da clínica.

Este trabalho tem por objetivo apresentar o conceito de Executivo Central, enfatizando principalmente suas origens e suas relações com teorias e conceitos que com ele guardam vizinhança.

\section{O conceito de Executivo Central: $O$ Contexto de sua Proposição Inicial}

O Executivo Central foi proposto inicialmente como um componente da memória de trabalho, que consiste em um modelo revisado e expandido de memória de curto prazo.

A concepção clássica de memória compreende um sistema composto de três sub-sistemas relativamente independentes: memória sensorial, memória de curto-prazo e memória de longo-prazo. Os estudos em torno deste modelo clássico procuraram determinar as evidências de que a memória não é um sistema único, mas sim composto de sub-sistemas. Além disso, tiveram por objetivo determinar a capacidade e o tipo de codificação característicos de cada um desses subsistemas (Baddeley, 1986; para uma apresentação didática destes modelos, em português, veja Sternberg, 2000). 
Na concepção clássica, cada sub-sistema de memória funcionava como um armazenador de informação: a memória sensorial manteria a informação durante algumas centenas de milissegundos, a memória de curto-prazo durante alguns segundos ou poucos minutos e a memória de longo-prazo seria capaz de manter a informação por dias, meses, anos e até toda uma vida. As informações seriam transferidas da memória sensorial para a memória de curto prazo e desta para a memória de longo-prazo, durante o processo de armazenamento (Baddeley, 1986).

Baddeley e Hitch (1974) propuseram que a memória de curto-prazo não constitui apenas uma instância de armazenagem temporária de informação, mas sim uma memória de trabalho. Toda e qualquer tarefa cognitiva envolve o processamento de informação proveniente do ambiente ou da própria memória do indivíduo e o lugar onde esse processamento ocorre é exatamente a memória de trabalho. A memória de curto-prazo passou, assim, a ser concebida não apenas como um armazenador temporário de informação, mas como um sistema para manter e operar com informações durante a execução de tarefas cognitivas como, por exemplo, compreensão de fala, aprendizagem e raciocínio: uma memória de trabalho.

Uma conseqüência direta da mudança de abordagem da memória de curto-prazo, trazida por Baddeley e Hitch (1974), é que além da parte do sistema envolvida com o armazenamento temporário de informação, tornou-se necessário propor um subsistema controlador, o Executivo Central, responsável pelo gerenciamento das manipulações e operações com representações que ocorrem na memória de trabalho.

Na proposta inicial, a memória de trabalho compreendia dois sub-sistemas que funcionam como armazenadores de informação: a alça fonológica - que possibilita a manutenção da informação de cunho fonológico e particularmente de cunho verbal, e o rascunho visuo-espacial - especializado na armazenagem temporária de informação visual e espacial. A alça fonológica, além de funcionar como um armazém de informações verbais, possui um mecanismo de repetição sub-vocal da informação que evita que ela se degrade durante sua estadia na alça (Baddeley \& Hitch, 1974).

Assim, a informação que adentra a mente, proveniente do meio externo, se for constituída de palavras, por exemplo, será mantida durante um curto espaço de tempo, enquanto está sendo processada, na alça fonológica. Se a informação for constituída por imagens, por exemplo, será mantida no rascunho visuo-espacial.

Posteriormente foi proposto um terceiro sub-sistema que também tem função de armazenamento: o buffer episódico (Baddeley, 1998). Esse terceiro componente da memória de trabalho permite a integração de informações fonológicas, visuais e espaciais que adentram a mente, sejam elas provenientes do mundo externo ou da própria memória de longo-prazo. Nele seria criada uma representação multimodal e temporal da situação atual.

Os sub-sistemas de armazenagem são gerenciados e controlados pelo Executivo Central (Baddeley, 1986). O Executivo Central está envolvido com o desenvolvimento de estratégias que possibilitam o aumento da capacidade de armazenamento dos sub-sistemas a ele subordinados. Por exemplo, a capacidade da alça fonológica, span auditivo, é de cinco a nove itens, capacidade essa da memória de curto-prazo já apontada por George Miller em seu artigo clássico O mágico número sete (Miller, 1956). No entanto, em uma tarefa em que deve manter, durante alguns minutos, quantidade de dígitos maior do que a capacidade da alça fonológica (por exemplo: 75926354843 9), um indivíduo pode recorrer ao agrupamento destes itens em pares ou trios (por exemplo: 759263548439 ou 759263 548 439). Neste caso, ao invés de manter 12 itens, estará mantendo seis ou quatro itens na memória de trabalho, o que está perfeitamente dentro da capacidade daquele sistema.

Além de contribuir com mecanismos que evitam o decaimento da informação e aumentam a capacidade da memória de trabalho, o Executivo Central atua no recrutamento e gerenciamento de outros sistemas durante a execução de tarefas cognitivas (Baddeley, 1986).

Um exemplo tornará mais claras as funções desempenhadas pelos diferentes componentes da memória de trabalho e, em especial, pelo Executivo Central. Diante de um problema de aritmética, enunciado para um indivíduo, este deve ser capaz, antes de qualquer outra coisa, de manter o enunciado do problema armazenado por tempo suficiente para que possa processá-lo. Esta manutenção é implementada na alça fonológica. A fim de estender o tempo de manutenção dessas informações, evitando sua perda prematura, o indivíduo pode lançar mão de repetição sub-vocal ou mesmo em voz alta. Os passos seguintes se referem ao processamento propriamente dito da informação e incluem: a compreensão do enunciado do problema, o estabelecimento de um algoritmo para sua solução, a implementação da solução e a apuração da exatidão do resultado encontrado. A compreensão do enunciado requer o recrutamento do processador especializado em linguagem que contém o conhecimento relativo a fonologia, sintaxe e semântica. A seguir, será necessária a construção de algum tipo de representação do problema, que conduzirá o indivíduo à seleção de algoritmos matemáticos apropriados, disponíveis na memória de longoprazo. Finalmente, o indivíduo executará os algoritmos e irá monitorar esse processo, a fim de chegar ao objetivo que é a solução do problema. Todo esse processo é gerenciado pelo Executivo Central, desde a ativação de mecanismos de repetição que garantem a manutenção do enunciado na memória de trabalho, o recrutamento do processador de linguagem, a busca e seleção dos algoritmos adequados na memória de longo prazo, sua execução e monitoração, até o recrutamento do módulo de linguagem para a emissão da resposta. E todo o processo ocorre no lugar virtual chamado memória de trabalho.

Entre o artigo de 1974 (Baddeley \& Hitch, 1974) que propõe o novo modelo e o livro de Baddeley de 1986, onde o autor o revisa, a alça fonológica e o rascunho visuo-espacial foram extensiva e intensivamente explorados e caracterizados, em detrimento do Executivo Central.

Em 1986, Baddeley realçou a necessidade de um detalhamento do Executivo Central e reconheceu no Sistema Atencional Supervisor, que havia sido proposto contemporaneamente por Norman e Shallice (1980, 1986), a melhor caracterização existente até aquele momento para o seu Executivo Central. 


\section{Sistema Atencional Supervisor, Controlador Pré-programado e Organização do Comportamento}

O Sistema Atencional Supervisor, equalizado ao Executivo Central por Allan Baddeley, foi proposto por Norman e Shallice $(1980,1986)$ no contexto de seus estudos sobre atenção.

A Psicologia Cognitiva concebe a mente humana como um processador de informação (Gardner, 1985). No entanto, a todo instante o indivíduo é bombardeado por um número extremamente grande de informações provenientes do meio externo e de seus próprios registros mnêmicos. Esta situação, acoplada a capacidade limitada de processamento da mente (Gardner, 1985), impõe a necessidade de mecanismos de seleção de informação, isto é, mecanismos atencionais.

Shiffrin e Schneider (1977) estudaram a seleção de informações no contexto da percepção, isto é, como ocorre o direcionamento da atenção de alguém para dado estímulo em detrimento de todos os outros disponíveis em determinado momento. Observaram a existência de dois modos básicos de seleção de estímulos: processos atencionais automáticos e processos atencionais controlados.

É comum a experiência de captura da atenção, sem que haja qualquer deliberação do indivíduo quanto a esta ocorrência. Esta experiência está associada aos processos atencionais automáticos. Por exemplo, se em uma festa o traje a rigor foi recomendado no convite e alguém comparece vestido com agasalho de ginástica, todos os olhares se voltarão para ele assim que entrar no salão, pois destoará dramaticamente de todos os outros a sua volta. Um estímulo discrepante em relação àqueles que o rodeiam é selecionado de forma automática.

O direcionamento automático da atenção pode decorrer também de processo de aprendizagem, o indivíduo pode aprender a selecionar um estímulo em detrimento de outros. Por exemplo, um indivíduo pode ser condicionado a direcionar a atenção para uma determinada localização do espaço sem que se dê conta disso. Um modo de fazê-lo seria, durante um jogo de computador, mostrar os estímulos no canto direito com maior frequiência do que nas outras regiões da tela. Após algum tempo de jogo o sujeito começaria a responder muito mais rapidamente a estímulos que ocorressem nessa região da tela do que em outro lugar. Esta locação seria selecionada em primeiro lugar em detrimento das outras possíveis como resultado do processo de condicionamento. Para responder a um estímulo que ocorresse em outro lugar, teria que se libertar da captura da atenção pelo canto direito da tela e só então o direcionamento da atenção poderia se dar para outra locação.

Os dois exemplos de captura de atenção ilustram os processos atencionais automáticos. No entanto, o direcionamento da atenção também pode se dar de modo controlado: o indivíduo escolhe os estímulos, os seleciona a partir da vontade. Retomando o exemplo da festa de traje a rigor, uma convidada mais exigente pode dedicar a noite a examinar as vestimentas para depois comentar com as amigas, talvez direcionando seu exame (a atenção) de forma tendenciosa para outras mulheres menos queridas suas nas quais procuraria os defeitos. Isto seria um exemplo de processo atencional controlado.

Norman e Shallice $(1980,1986)$ também estudaram os processos de seleção de informação, não no contexto da percepção como Schiffrin e Schneider (1977), mas no contexto da ação, ou seja, os mecanismos de seleção de respostas. De forma análoga ao observado por Shiffrin e Schneider, Norman e Shallice identificaram dois modos básicos de seleção de respostas: automático e controlado. Existem respostas que estão atreladas a certos estímulos, de modo que uma vez diante do estímulo, a resposta é selecionada de forma automática, sem o controle do indivíduo. É claro que, principalmente em se tratando de humanos, este não é o único modo de seleção de respostas e, aliás, com freqüência é requerida do indivíduo a inibição de uma resposta automática em favor de uma resposta controlada pela vontade.

A partir da constatação da existência de processos automáticos e de processos controlados de seleção de respostas, Norman e Shallice propuseram um modelo composto por dois sistemas: um organizador pré-programado e um Sistema Atencional Supervisor (SAS).

O organizador pré-programado, mediante determinados estímulos especificados previamente, seleciona de modo automático respostas de um repertório já existente, sendo suficiente para controlar ações bem aprendidas ou muito simples. O SAS, por sua vez, entra em ação quando respostas disponíveis no repertório do indivíduo não atendem às necessidades, sendo necessária a modificação dessas ou mesmo a construção de respostas novas, através de controle consciente e voluntário (Tirapu-Ustárroz, Muñoz-Céspedes \& Pelegrín-Valero, 2002).

O modelo em questão pressupõe a existência de representações de respostas armazenadas na memória. As representações de respostas complexas são conhecidas. em Psicologia Cognitiva, como esquemas. Cada indivíduo dispõe de um grande conjunto de esquemas, constituídos a partir da experiência passada e das características intrínsecas ao sistema. Por exemplo, durante as aulas de direção, um aprendiz de motorista constrói um conjunto de esquemas que representa as ações envolvidas no comportamento complexo de dirigir. Esses esquemas passarão a controlar o comportamento quando o indivíduo se tornar um motorista experiente.

O nível de ativação de cada esquema pode ser aumentado como resultado da exposição a determinados estímulos e, uma vez ultrapassado o limiar de ativação, o esquema será selecionado. Os estímulos disparadores e o limiar de ativação para seleção são pré-especificados no próprio esquema (Norman \& Sallice, 1980, 1986).

Retomando o exemplo do comportamento de dirigir, pode-se conceber que sua representação compreende um conjunto de esquemas, cada um tendo disparadores préespecificados. Por exemplo, ao ouvir o barulho do motor do carro (disparador) requerendo outra marcha, o esquema de mudança de marcha, que compreende uma seqüência de ações como não acelerar, pisar na embreagem e mudar a marcha, é automaticamente recrutado. O motorista não precisa dedicar recursos atencionais para essa seqüência de comportamentos, eles vão sendo selecionados nos momentos adequados, com rapidez suficiente para garantir sua eficiência. Enquanto tudo isso se passa, o motorista pode estar 
envolvido em outro comportamento complexo, como uma conversa com seu companheiro de viagem. Este é o modo de seleção executado pelo organizador pré-programado; uma seleção automática que não necessita de recursos atencionais ou decisões conscientes, determinada pelas características e pela história do sistema.

Dentre as características do sistema, determinantes do modo de operação do organizador pré-programado, está a competição (mutuamente inibitória) por seleção (Cooper, 2002). Por exemplo, pode-se conceber que o esquema de frear e aquele de acelerar, que representam ações mais elementares que compõem o comportamento de dirigir, devem interagir de modo que a elevação da ativação de um deles tenha efeito inibitório sobre o outro, reduzindo o nível de ativação e sua chance de seleção.

O modo de seleção de respostas do organizador préprogramado possibilita respostas rápidas e precisas, visto que essas estão disponíveis na forma de esquemas já executados e testados, apenas aguardando seleção. No entanto, essa vantagem tem o preço de uma certa rigidez. Uma vez ultrapassado o limiar de ativação de dado esquema, e determinada sua seleção, esse permanece ativo até que a ação seja concluída e o objetivo atingido, a menos que seja inibido por um esquema competidor ou pelo sistema controlador voluntário, o SAS. Essa rigidez pode, inclusive, resultar em atos falhos (Cooper, 2002). Uma pessoa pode tomar o caminho do trabalho (ação que faz na maioria dos dias ao entrar no carro pela manhã, e cujo esquema tem limiar de ativação mais baixo em função da freqüência com que é ativado) quando, na verdade, é domingo e decidiu ir a uma praia mais distante de carro.

A flexibilidade na seleção de comportamentos é garantida pelo Sistema Atencional Supervisor (LaBerge, 2002). O SAS tem acesso às intenções, às representações do meio, armazenadas na memória ou percebidas de forma mais imediata e aos processadores de informação de que dispõe o indivíduo. A partir dessas diferentes fontes de informações, regula o comportamento voluntário, modulando o nível de ativação de esquemas já existentes ou construindo seqüências originais de esquemas que dêem conta de situações novas para as quais o indivíduo não dispõe de esquemas. Seus mecanismos básicos de ação são planejamento, monitoração e ajuste das respostas de acordo com os planos e intenções do indivíduo.

Voltar ao exemplo de dirigir para o trabalho ao invés de dirigir para a praia, pode ser de auxílio para entender a interação entre o SAS e o controlador pré-programado. O indivíduo, cansado de uma longa semana, toma a decisão de passear na praia para esquecer as pendências que o aguardam no trabalho. Com essa intenção, formula-se um plano de ação e os esquemas apropriados à execução deste têm seu nível de ativação elevado. No entanto, a preocupação (motivação) pode se somar ao já elevado valor de ativação do esquema dirigir para o trabalho, favorecendo sua seleção em detrimento de dirigir para a praia, desvirtuando o indivíduo do plano inicial de dar um passeio para se distrair. Ao monitorar o comportamento, isto é, conferir se o indivíduo está se aproximando de seu objetivo consciente inicial, o SAS detecta o erro e modula o nível de ativação dos esquemas dirigir para o trabalho e dirigir para a praia, de modo a elevar o nível de ativação do segundo em detrimento do primeiro, e o selecionar, retificando o rumo do indivíduo de acordo com seu objetivo inicial. O SAS não ativa este ou aquele esquema, mas atua modulando o nível de ativação deles, impondo tendenciosidade no processo seletivo (LaBerge, 2002; Tirapu-Ustárroz \& cols., 2002)

É possível inferir do que foi dito até agora a importância de um sistema como o SAS para processos e fenômenos do pensamento como: tomada de decisão, resolução de problemas e criatividade. O modelo de Norman e Shallice continua a ser foco de interesse e tem sido explorado tanto no que se refere a tentativas de maior especificação do funcionamento do SAS e do Controlador Pré-programado (Cooper, 2002; LaBerge, 2002; Tirapu-Ustárroz \& cols., 2002) quanto em estudos aplicados, por exemplo, relacionados a patologias como esquizofrenia e TDAh (Bayliss \& Roodenrys, 2000; Chan, Chen, Cheung \& Cheung, 2004).

Segundo Baddeley (1986), o SAS é o próprio Executivo Central, o sistema cognitivo que gerencia todo o processamento mental de informação, que se passa na memória de trabalho. Norman e Shallice detalharam o modo de funcionamento desse sistema e esclareceram sua relação com os mecanismos atencionais.

\section{O Executivo Central ou SAS e a Unidade para Programar, Monitorar e Regular a Atividade de Luria}

De acordo com Shallice (1988), o SAS é uma edição, na linguagem do processamento da informação vigente na Psicologia Cognitiva, da unidade para programar, monitorar e regular a atividade, proposta por Luria $(1966,1973)$ no contexto da neuropsicologia.

Luria, a partir do estudo clínico de pacientes com lesões cerebrais, propôs um modelo de organização de funções no cérebro composto por três principais unidades funcionais: uma unidade para regular o tono ou a vigília, uma outra para obter, processar e armazenar as informações que chegam do mundo exterior e uma terceira para programar, regular e verificar a atividade mental. De acordo com Luria, as funções mentais são sistemas funcionais complexos formados ao longo do desenvolvimento do indivíduo, implementadas a partir de interações específicas entre as três unidades funcionais do cérebro (Luria, 1966, 1973).

A unidade para programar, regular e verificar a atividade mental corresponde aos aspectos laterais das áreas préfrontais e tem por função a regulação do comportamento intencional. Esta regulação compreende a criação de intenções, a elaboração de planos e programas de respostas, a avaliação da execução desses planos e a determinação dos ajustes necessários para que se atinja a consecução das intenções que originaram o comportamento.

A concepção de uma unidade funcional do cérebro, que serve de substrato para uma estrutura mental voltada para o controle voluntário do comportamento, guarda relação com um dos principais axiomas da psicologia cognitiva soviética: o comportamento humano, diferente daquele de outros animais, não resulta apenas de sua história passada, mas também e, principalmente, da sua história futura enquanto representada em seus planos e intenções. Assim, o comportamento não é somente a resultante das aprendizagens ocorridas ao longo da vida, mas depende também da influência da vonta- 
de. Luria e Vigotsky (Luria, 1987; Luria \& Ydovich, 1987; Vigotsky, 1962) ainda vão além, afirmando que a influência dos planos e intenções pode (e na maioria das vezes o faz) sobrepujar aquela das respostas aprendidas.

Luria (1966) observou que lesões pré-frontais laterais acarretam comprometimento grave do comportamento voluntário (controlado), estando preservados aqueles comportamentos selecionados e executados sem a participação da vontade. $\mathrm{O}$ indivíduo fica à mercê da sua história de aprendizagens e dos mecanismos de funcionamento intrínsecos da mente (para uma descrição bastante acessível, em português, das alterações de comportamento observadas em pacientes com lesões pré-frontais, veja Goldberg, 2002).

No que se refere ao funcionamento da atenção, por exemplo, mediante lesões pré-frontais, os mecanismos de captura automática da atenção estão preservados. No entanto, observa-se dificuldade (ou mesmo impossibilidade) de modulação desses mecanismos pela vontade. Um paciente deitado em seu leito de hospital se voltará para olhar na direção de um grande estrondo (mecanismo atencional automático) causado por um funcionário que deixou cair uma pilha de bandejas que carregava em seu carrinho, mas apresentará uma inércia muito acima do normal para se voltar e responder ao residente novato que lhe pergunta se ele lembra porque está internado. Muitas vezes a pergunta se perderá sem uma resposta. Para responder a pergunta ele terá que se libertar do efeito de captura que o grande barulho exerceu sobre a atenção e direcionar, voluntariamente, o foco atencional para um estímulo bem menos pregnante: o residente que lhe fala em voz baixa para não incomodar os outros doentes.

As alterações decorrentes de uma lesão pré-frontal não atingem apenas a atenção, mas todos os processos cognitivos voluntários. Em relação à linguagem, observa-se que, de modo geral, a articulação, a sintaxe e até muitos aspectos da semântica encontram-se preservados. No entanto, o discurso se apresenta desorganizado em função da dificuldade do paciente mantê-lo orientado por sua intenção. A lógica que rege a seleção do tema, das sentenças e das palavras é aquela da pregnância dos estímulos que o atingirão durante a produção do discurso. Por exemplo, ao relatar como foi o fim de semana na praia, o paciente olha de repente para o gravador sobre a mesa e introduz em seu relato comentários sobre uma entrevista que deu há algum tempo sobre o descaso da prefeitura em relação ao calçamento da rua em que mora (a um jornalista que usava um aparelho similar). Esta nova direção assumida pelo discurso pode ser mantida por um dado tempo até que um novo rumo se imponha, mas não pela vontade do paciente. Uma outra ocorrência freqüente na fala desses indivíduos é a intrusão de palavras inapropriadas ao tema sendo tratado, simplesmente porque têm vizinhança fonológica ou semântica com a palavra que seria produzida. Por exemplo, ao tentar dizer que estava ventando muito na praia, pode dizer que estava chovendo ou até nevando muito.

Os processos de pensamento também se apresentam afetados pela dificuldade de conceber planos a partir das suas próprias intenções e de manter-se atrelado a esse plano até a consecução do objetivo de maneira coerente com sua intenção inicial. Assim, diante de um problema de aritmética o paciente ouve o enunciado e o codifica, mas tem dificuldade para estabelecer um algoritmo adequado para solucioná-lo ou até consegue construir o início de um algoritmo, mas pode abortar a solução no primeiro cálculo que faz, deixando de executar os passos seguintes do seu próprio algoritmo, porque não monitora se atingiu o objetivo inicial determinado a partir de uma intenção sua.

As ações motoras também se apresentam mais dependentes dos efeitos do ambiente e da história das aprendizagens do que das intenções do paciente. Por exemplo, o paciente levanta-se de sua cama para ir até a janela olhar o movimento na rua. No caminho passa pela porta do quarto e simplesmente a abre e sai. Portas servem para serem abertas ou fechadas e se passar através delas, e essa ação superaprendida se impõe em detrimento da decisão voluntária de ir até a janela para dar uma olhada.

Observações como essas, aliadas à idéia de que em humanos o comportamento não depende apenas da história passada, mas também, e principalmente, da história futura (planos e intenções) levaram Luria a propor que as áreas pré-frontais constituem uma unidade funcional do cérebro cuja função é exatamente a organização do comportamento voluntário.

\section{Conclusão}

Luria (1966, 1973) estudou as relações entre funções mentais e o cérebro e observou que as regiões pré-frontais constituem uma unidade funcional para organização da atividade mental e do comportamento. Observou que pacientes com lesões pré-frontais apresentam preservados os comportamentos mais elementares, que dependem da história das aprendizagens, mas apresentam uma desintegração dos comportamentos regidos por metas e intenções, o comportamento voluntário.

Norman e Shallice (1980, 1986), ao estudarem a atenção e, em particular os mecanismos de seleção de comportamentos, ações, observaram dois modos básicos de seleção: processos automáticos e processos controlados. Em situações para as quais o indivíduo dispõe de um repertório de comportamentos já aprendidos, a seleção da ação se dá de forma automática. Quando não dispõe de um repertório de comportamentos armazenado, o indivíduo é chamado a elaborar planos originais de comportamento; nesses casos, os processos controlados são requeridos.

A partir dessa formulação e das observações adiantadas por Luria $(1966,1973)$ a respeito de pacientes pré-frontais, Norman e Shallice (1980, 1986) propuseram dois sistemas de processamento de informação responsáveis pela seleção de comportamentos: o Sistema Pré-programado e o Sistema Atencional Supervisor.

O Sistema Pré-programado inclui as representações, armazenadas na memória, dos comportamentos aprendidos ao longo da história do indivíduo, assim como mecanismos de seleção pré-estabelecidos. Um desses mecanismos é o nível de ativação da representação (esquema). O nível de ativação de um esquema se eleva quando o estímulo disparador desse esquema (pré-estabelecido na própria representação) se apresenta ao indivíduo. $\mathrm{O}$ nível de ativação de um esquema também depende da freqüência com que ele é ativado: quanto 
maior a freqüência, maior o nível inicial de ativação e mais facilitada é a seleção do esquema.

O Sistema Atencional Supervisor, cuja idéia embrionária encontra-se na unidade para programar e regular a atividade mental proposta por Luria, teve seus mecanismos de atuação e de interação com o Sistema Pré-programado especificados por Norman e Shallice. Assim, foi proposto que o SAS modula a seleção que se opera através do Sistema Pré-programado, alterando, por exemplo, o nível de ativação dos esquemas de acordo com as intenções do indivíduo, possibilitando que este não fique apenas à mercê de sua história de aprendizagens, mas que possa gerenciar suas ações a partir de suas intenções.

Norman e Shallice $(1980,1986)$ traduziram para a linguagem do processamento da informação a idéia evidenciada por Luria e Vigotsky de que nem tudo no comportamento humano depende da história das aprendizagens do organismo, resgatando a importância das intenções no controle do comportamento. Vale lembrar que estas idéias não foram apresentadas pela primeira vez por Luria e Vigotsky, mas dizem respeito a uma tradição racionalista em Filosofia e Psicologia.

A contribuição de Norman e Shallice pode ser enunciada como um detalhamento dos mecanismos subjacentes aos processos controlados e automáticos e à interação entre eles, resgatando conceitos e teorias da Psicologia Cognitiva referentes à memória de longo-prazo, à atenção e às representações. Foi exatamente este detalhamento que chamou a atenção de Baddeley, que propusera a idéia da memória de curto-prazo como uma memória de trabalho, tornando necessária a previsão de mecanismos de controle para este trabalho. Baddeley, entre 1974 (Baddeley \& Hitch, 1974) e 1986 (Baddeley, 1986) desenvolveu o modelo de memória de trabalho se referindo todo o tempo a um controlador (o Executivo Central), mas pouco ou nada especificara a respeito de como esse controle era implementado.

Ao adotar as especificações de Norman e Shallice referentes ao SAS e ao Sistema Pré-programado, para o seu Executivo Central, Baddeley vislumbrou as consequiências dessa adoção. A principal dessas conseqüências é que a conexão entre memória e atenção, que qualquer um intuiria a partir da própria experiência, foi prevista e especificada no nível da teoria (Baddeley, 1986; Helene \& Xavier, 2003). A memória de curto-prazo, vista como uma memória de trabalho, é um sistema de memória no que diz respeito às suas funções de armazenagem, mas é também um sistema atencional, na medida em que seu componente Executivo Central gerencia a atividade mental.

O conceito de Executivo Central continua sendo objeto de grande interesse em Psicologia e Neuropsicologia. Nos últimos 10 anos, a unidade do Executivo Central, assim como dos outros componentes da memória de trabalho, vem sendo questionada (Baddeley, 1996, 1998): seria este sistema um controlador unitário ou composto por um conjunto de controladores, com funções específicas, atuando em paralelo? Essa questão se impôs, inicialmente, a partir da variedade de déficits executivos observados em pacientes neurológicos; a presença de comprometimento de uma função executiva não garante a observação de outros déficits executivos (Baddeley, 1996). Atualmente, as evidências favoráveis ao fracionamen- to do Executivo Central não são apenas baseadas em pacientes neurológicos, mas também são proveniente de estudos com primatas não-humanos ou com imagens funcionais do cérebro de indivíduos normais durante a execução de tarefas que requerem a participação do EC.

Enquanto não se encontra uma resposta direta à questão do fracionamento, a estratégia tem sido identificar subprocessos, especificando-os e desenvolvendo métodos de mensuração e análise, na expectativa de que os dados assim obtidos irão culminar na resposta à questão principal. Assim, sub-componentes e seus correlatos neurais vêm sendo identificados, voltados para as seguintes funções executivas: 1) compartilhamento de tempo e recursos entre duas ou mais atividades executadas simultaneamente (Baddeley \& Della Sala, 1996; Bourke, Duncan \& Nimmo-Smith, 1996); 2) codificação de informações na memória episódica e 3) recuperação de informações armazenadas na memória episódica (Shallice \& col., 1994; Tulving, Markowitsch, Craik, Habib \& Houle, 1996); 4) manutenção de informação na memória de trabalho (Cohen \& col., 1997; Goldman-Rakic, 1988); 5) manutenção de um conjunto de objetivos que atuam como orientadores do comportamento (Duncan, Burgess \& Emslie, 1995; Duncan, Emslie, Williams, Johnson \& Freer, 1996).

Disfunções do Executivo Central têm sido apontadas em diferentes patologias do desenvolvimento como no TDAh, dificuldades específicas de aprendizagem e transtornos invasivos do desenvolvimento. Em função dessas observações, as mudanças ocorridas ao longo da infância e adolescência no funcionamento do Executivo Central, na patologia ou no desenvolvimento normal, vêm sendo alvo de interesse de laboratórios de Psicologia Cognitiva dentro e fora do Brasil. É preciso compreender como se apresentam os processos de controle do comportamento voluntário em diferentes idades e que fatores operam para o seu desenvolvimento ao longo da infância. Esse conhecimento será crucial para a clínica psicológica destas patologias. Situar teórica e historicamente as origens do conceito de Executivo Central traz consigo a sugestão de que a teorização do desenvolvimento deste sistema talvez obtenha subsídios interessantes se retomar suas origens aqui. Assim, a Psicologia soviética, que tem por axioma a formulação de que em humanos o comportamento não depende apenas da história passada, mas também, e principalmente, da história futura (planos e intenções) e que vê no estudo do desenvolvimento dos processos cognitivos o principal método da Psicologia pode ser uma boa e fértil fonte inicial de idéias para este empreendimento teórico.

\section{Referências}

Baddeley, A. D. (1986). Working Memory. Oxford: Clarendon Press.

Baddeley, A. D. (1996). The fractionation of working memory. Proceedings National Academy of sciences, 93, 1346813472.

Baddeley, A. D. (1998). Recent developments in working memory. Current opinion in Neurobiology, 8, 234-238.

Baddeley, A. D. \& Della Sala, S. (1996). Working memory and executive control. Proceedings of the Royal Society of London (Biology), 351, 1397-1484. 
Baddeley, A. D. \& Hitch, G. J. (1974). Working Memory. Em G. A. Bower (Org.), Recent Advances in Learning and Motivation Vol. VIII (pp. 47-89). New York: Academic Press.

Bayliss, D. M. \& Roodenrys, S. (2000). Executive processing and attention deficit hyperactivity disorder: an application of the supervisory attentional system. Developmental Neuropsychology, 17(2), 161-80.

Bourke, P. A., Duncan, J. \& Nimmo-Smith, I. (1996). A general factor involved in dual-task performance decrement. Quarterly Journal of Experimental Psychology, 49A, 525-545.

Brosnan, M., Demetre, J., Hamill, S., Robson, K., Shepherd, H. \& Cody, G. (2002). Executive functioning in adults and children with developmental dyslexia. Neuropsychologia, 40(12), 2144-2155.

Chan, R. C., Chen, E. Y., Cheung, E. F. \& Cheung, H. K. (2004). Executive dysfunctions in schizophrenia. Relationships to clinical manifestation. European Archives of Psychiatry and Clinical Neuroscience, 254(4), 256-62.

Charchat-Fichman, H., Caramelli, P., Sameshima, K. \& Nitrini, R. (2005). Declínio da capacidade cognitiva durante o envelhecimento. Revista Brasileira de Psiquiatria, 27(1), 79-82.

Charchat-Fichman, H., Nitrini, R., Caramelli, P. \& Sameshima, K. (2001). Investigação de Marcadores Clínicos dos Estágios Iniciais da Doença de Alzheimer com Testes Neuropsicológicos Computadorizados. Psicologia: Reflexão e Crítica, 14(2), 305-316.

Cohen, J. D., Perlstein, W. M., Braver, T. S., Nystron, L. E., Noll, D. C., Jonides, J. \& Smith, E. E. (1997). Temporal dynamics of brain activation during a working memory task. Nature, $386,604-608$.

Cooper, R. (2002). Order and disorder in everyday action: the roles of contention scheduling and supervisory attention. Neurocase, $8(1), 61-79$.

Duncan, J., Burgess, P. \& Emslie, H. (1995). Fluid intelligence after frontal lobe lesions. Neuropsychologia, 33, 261-268.

Duncan, J., Emslie, H., Williams, P., Johnson, R. \& Freer, C. (1996). Intelligence and the frontal lobe: the organization of goaldirected behaviour. Cognitive Psychology, 30, 257-303.

Galera, C. \& Fuhs, C. C. L. (2004). Memória visuo-espacial a curto prazo: os efeitos da supressão articulatória e de uma tarefa aritmética. Psicologia: Reflexão e Crítica, 16(2), 337-348.

Gardner, H. (1985). The mind's new science: a history of the Cognitive Revolution. New York: Basic Books, Inc.

Goldberg, E. (2002). O cérebro executivo. Rio de Janeiro: Imago.

Goldman-Rakic, P. W. (1988). Topography of cognition: parallel distributed networks in primate association cortex. Annual Review of Neurosciences, 11, 137-156.

Happe, F. \& Frith, U. (1996). The neuropsychology of autism. Brain, 119(4), 1377-1400.

Helene, A. F. \& Xavier, G. A. (2003). A construção da atenção a partir da memória. Revista Brasileira de Psiquiatria, 25(Supl. II), $12-20$.

Henry, L. A. (2001). How does the severity of a learning disability affect working memory difficulties. Journal of Experimental Child Psychology, 74(3), 240-60.

Hill, E. L. \& Frith, U. (2003). Understanding autism: insights from mind and brain. Philosophy Transactions of the Royal Society of London B: Biological Sciences, 358(1430), 281-289.
Jeffries, S. \& Everatt J. (2004). Working memory: its role in dyslexia and other specific learning difficulties. Dyslexia, 10(3), 196-214.

Karatekin C. (2004). A test of the integrity of the components of Baddeley's model of working memory in attention-deficit/ hyperactivity disorder (ADHD). Journal of Child Psychology and Psychiatry, 45(5), 912-926.

LaBerge, D. (2002). Attentional control: brief and prolonged. Psychological Research, 66(4), 220-33.

Lopes, E. J., Lopes, R. F. F. \& Galera, C. A. (2005). Memória de trabalho viso-espacial em crianças de 7 a 12 anos. Estudos de Psicologia, 10(2), 207-214.

Luria, A. R. (1966). Higher cortical functions in man. London: Tavistock.

Luria, A. R. (1973). The working brain. London: Penguin.

Luria, A. R. (1987). Pensamento e Linguagem: as últimas conferências de Luria. Porto Alegre: Artes Médicas.

Luria A. R. \& Yudovich, F. I. (1987). Linguagem e desenvolvimento intelectual da criança. Porto Alegre: Artes Médicas.

Malloy-Diniz, L. F., Cardoso-Martins, C., Carneiro, K. C., Cerqueira, M. M. M., Ferreira, A. P. A., Aguiar, M. J. B. \& Starling, A. L. (2004). Funções executivas em crianças fenilcetonúricas. Variações em relação ao nível de fenilalanina. Arquivos de Neuropsiquiatria, 62(2-B), 473-479.

Martinussen, R., Hayden, J., Hogg-Johnson, S. \& Tannock, R. (2005). A meta-analysis of working memory impairments in children with attention-deficit/hyperactivity disorder. Journal of American Academy of Child and Adolescent Psychiatry, 44(4), 377-384.

Miller, G. A. (1956). The magical number seven, plus or minus two: Some limits on our capacity for processing information. Psychological Review, 63, 81-97.

Norman, D. A. \& Shallice, T. (1980). Attention to Action. Willed and automatic control of behavior (Chip report 99). San Diego: University of California.

Norman, D. A. \& Shallice, T. (1986). Attention to Action. Willed and automatic control of behavior. Em R. J. Davidson, G. E. Schwartz \& D. Shapiro (Orgs.), Consciousness and selfregulation (vol. 4). New York: Plenum Press.

Parente, M. A. M. P., Sparta, M. \& Palmini, A. L. (2001). Distúrbio de Percepção Temporal e sua Influência na Memória: Estudo de Caso de Paciente com Lesão Frontal. Psicologia: Reflexão e Crítica, 14(2), 343-352.

Planche, P. (2002). Information processing in autistic children: more sequential or more simultaneous? International Journal of Circumpolar Health, 61(2), 4-14.

Roth, R. M. \& Saykin, A. J. (2004). Executive dysfunction in attention-deficit/hyperactivity disorder: cognitive and neuroimaging findings. The Psychiatric Clinics of North America, 27(1), 83-96.

Rozenthal, M., Laks, J. \& Engelhardt, E. (2004). Neuropsychological aspects of depression. Revista de Psiquiatria, 26(2), 204-212.

Shamay-Tsoory, S. G., Tomer, R., Yaniv, S. \& Aharon-Peretz, J. (2002). Empathy deficits in Asperger syndrome: a cognitive profile. Neurocase, 8(3), 245-252.

Sikora, M. D., Haley P., Edwards J. \& Butler R. W. (2002). Tower of London test performance in children with poor arithmetic skills. Developmental Neuropsychology, 21(3), 243-254.

Shallice, T. (1988). From Neuropsychology to Mental Structure. New York: Cambridge University Press. 
Shallice, T., Fetcher, P., Frith, C. D., Grasby, P., Frackowiak, R. S. J. \& Dolan, R. J. (1994). Brain regions associated with the acquision and retrieval of verbal episodic memory. Nature, 386, 633-635.

Shiffrin, R. M. \& Schneider, W. (1977). Controlled and Automatic Human Information Processing: II. Perceptual learning, automatic attending, and a general theory. Psychological Review, 84(2), 127-190.

Stanczak, D. \& Triplett, G. (2003). Psychometric properties of the Mid-Range Expanded Trail Making Test. An examination of learning-disabled and non-learning-disabled children. Archives of Clinical Neuropsychology, 18(2),107-20.

Sternberg, R. J. (2000). Psicologia Cognitiva. Porto Alegre: Artmed.

Tirapu-Ustárroz, J., Muñoz-Céspedes, J. M. \& Pelegrín-Valero, C. (2002). Executive functions: the need for the integration of concepts. Revista de Neurologia, 34(7), 673-85.
Tulving, E., Markowitsch, H. J., Craik, F. I. M., Habib, R. \& Houle, S. (1996). Novelty and familiarity activation in PET studies of memory encoding and retrieval. Cerebral Cortex, 6, 71-79.

Vigotsky, L. S. (1962). Thought and Language. Cambridge, Massachussets: MIT Press.

Weyandt, L. L. (2005). Executive function in children, adolescents, and adults with attention deficit hyperactivity disorder: introduction to the special issue. Developmental Neuropsychology, 27(1), 1-10.

Recebido em 23.05.2006 Primeira decisão editorial em 22.08.2006 Versão final em 08.02.2007 Aceito em 29.03.2007

\section{NORMAS DE PUBLICAÇÃO}

São adaptadas de Publication Manual of the American Psychological Association (APA, 5a. Edição, 2001) e podem ser consultadas ao final de cada número (versão impressa ou online) ou no endereço: http://www.revistaptp.org.br 